\title{
Emotional Support Animals, Service Animals, and Pets on Campus
}

\author{
C. W. Von Bergen, Ph.D. \\ Southwestern Oklahoma State University
}

\begin{abstract}
For decades, universities have been accommodating physically disabled students who require guide dogs and other types of service animals. Within the past several years, however, mentally disabled students have increasingly petitioned colleges with no-pet policies to permit them to bring their animals on campus because they need a companion or emotional support animal to make college life easier and to reduce their stress, loneliness, depression, and/or anxiety. Institutions that unlawfully reject such requests are finding themselves in court and charged with disability discrimination. Schools are understandably confused about their obligation, if any, to waive their no-pet rules under these circumstances. This article discusses pets on campus and provides administrators guidance with respect to this increasingly contentious issue and to keep their organizations "out of the legal dog house."
\end{abstract}

Keywords: emotional support animals, mental disabilities, service animals, therapy animals, pets on campus

\begin{abstract}
We can barely hear them over the horizon; we can scarcely see them coming down the road and in the air; we can faintly feel their vibrations as they approach us; and we can catch a wisp of their scent in the breeze coming our way. They are monkeys, cats, ferrets, birds, goats, rats, mice, rabbits, potbellied pigs, snakes, ducks, gerbils, miniature horses, and other animals we are unable to recognize in the distance. As they draw near we see that they all are wearing insignia with the words: "Emotional Support Animal." What does this mean for college campuses?
\end{abstract}

T he issue of allowing animals to assist persons with disabilities in higher education has been challenging for postsecondary institutions in recent years (Rothstein \& Rothstein, 2009). Although "traditional" service animals, such as guide dogs to aid persons with physical disabilities, have been accommodated on campuses, the use of animals to assist individuals with psychiatric issues is a more recent trend (Huss, 2012). Within the past several years, colleges with no-pet policies have begun receiving more and more requests from students who claim the need for a "companion" or "emotional support animal" (ESA) as an accommodation for their mental, psychiatric, or emotional disorder 
(Degutis, 2014). Many postsecondary educational institutions are confused about their obligation, if any, to waive their pet bans under these circumstances. This article discusses some history related to mental disorders and mental health on campus, examines the current definitions of impairments and animals on campus, and recommends a number of actions (takeaways) that higher education officials may adopt with respect to, particularly, emotional support animals.

\section{MENTAL HEALTH CRISIS}

Approximately 61.5 million Americans, one in four adults, experience a mental health impairment in any year and one in 17, representing 13.6 million people, live with a serious mental illness, including schizophrenia, major depression, or bipolar disorder, that costs America \$193.2 billion in lost earnings per year (The National Alliance on Mental Illness, 2013). The number of people claiming that they have been discriminated against because of their mental disability has increased in recent years (Dessler, 2015), and now psychological disorders account for the second greatest number of disability claims, after musculoskeletal assertions. Moreover, the return of veteran students with disabilities - such as post-traumatic stress disorder (PTSD), traumatic brain injury, depression, substance abuse, substantial mobility limitations owing to brain and orthopedic injuries - from overseas conflicts, the enactment of the Americans With Disabilities Act Amendments Act of 2008 (ADAAA), and the passage of the Post-9/11 Veterans Assistance Act of 2008 places America's colleges and universities at the forefront of addressing the unique needs of these students (Grossman, 2009).

\section{Mental Illness Becoming More Common for College Students}

Many students today enter college already taking psychiatric medication and/or expecting mental health services when they arrive on campus (Watkins, Hunt, \& Eisenberg, 2012), and administrators have reported more difficult and severe long-term mental health issues and the emergence of less prevalent conditions such as Tourette's and Asperger's syndrome (Blanco et al., 2008). Twenge et al. (2010) found five times as many students in 2007 surpassed clinical cutoffs in one or more mental health categories, compared with those who took the measure several decades earlier. Interestingly, $75 \%$ of lifetime mental disorders have first onset by the typical college age range of 18-24 (Kessler et al., 2005).

There are numerous reasons for the increasing numbers of mentally ill students. It is becoming more acceptable to disclose a mental illness; therefore, more people are seeking out help. With counseling and other supportive services, students with a learning disability, mood disorder, or obsessive compulsive disorder that would not have been able to attend college and be successful just a few years ago are now able to do so (Kruisselbrink-Flatt, 2013). Finally, the transition from attending high school and living at home with one's family to living on their own requires some students to simultaneously adapt to the increased academic rigor of college courses and new responsibilities. For some, potentially new social and emotional stressors may be the first time that they have the responsibility of waking themselves up for classes, getting along with roommates, making new friends, or confronting choices about drinking and dating. These stressors can sometimes lead to mental health issues such as depression or anxiety. 


\section{The Increased Prominence of ESAs}

Some commentators have indicated that this intensification of students' psychological and emotional needs suggest a mental health crisis (e.g., Eiser, 2011). These data also suggest that this increased attention to mental disabilities and psychiatric impairments in American society will likely advance the agenda of individuals who advocate the acceptance of ESAs. Indeed, as a way of coping with this mental health state of affairs, college students are increasingly asking administrators to allow them to bring animals to campus and to exempt them from the institution's rules and practices that traditionally have upheld "no-pets" policies (or from very limiting regulations, such as the University of California at Santa Cruz policy [n.d.] which indicates: "No-pets [except fish in a 10-gallon tank or smaller aquarium] are allowed in the residential facilities"). Students are increasingly asserting that they have a mental or psychiatric impairment and that an animal provides them therapeutic benefit.

These requests are emblematic of the recent greater emphasis on mental disorders in U.S. society, which accelerated because of the Americans with Disabilities Act of 1990 (ADA), a comprehensive civil rights law that prohibits discrimination on the basis of disability. Among other issues, the ADA provides that individuals with disabilities must be granted access to public educational entities (state institutions) under Title II and places of public accommodation (private institutions) under Title III. Public accommodation includes "undergraduate, or postgraduate private school, or other place of education" (42 U.S.C. $12181(7)(J))$.

Over time, U.S. Supreme Court decisions whittled away at the definition of disability, narrowing the protections available to citizens and eroding Congressional intent of the law. Consequently in 2008, Congress enacted the Americans with Disabilities Act Amendments Act (ADAAA), and the nation reaffirmed its commitment to protect against discrimination of the disabled and to truly opening the doors of opportunity to all people with impairments. The objective of the ADAAA was to reinstate the original ADA's broad scope of protection for disabled individuals, thus making it easier for persons seeking the protection of the ADA to establish that they have a disability within the meaning of the statute. The ADAAA noted that the definition of disability must be construed "... in favor of broad coverage of individuals ..." (42 U.S. Code). The focus must be on whether discrimination occurred and not on whether a person meets the definition of disabled.

After the ADA and ADAAA passed, however, the statutes as applied to physical disabilities received the most attention (Moss, Johnson, \& Ullman, 1998), and significant progress in gaining access to public facilities, including restaurants, theaters, stores, museums, offices and plants, web sites, and government services, was made. Postsecondary institutions responded by building ramps, constructing elevators, removing architectural barriers in existing facilities, setting offset hinges to widen doorways, painting new lines to create accessible parking spaces, modifying furniture and equipment, and so forth, in order to accommodate persons with physical disabilities. Accommodations involving modifications or adjustments in policies, practices, procedures, or environments that enable qualified individuals with a disability to enjoy equal opportunities and access to university rights, privileges, benefits, and services are not required if they cannot be made "without much difficulty or expense" (42 U.S.C. § 12181(9) (2006)). 
Significantly less progress, though, has been made by individuals who have mental, emotional, or psychiatric disorders, which are often dubbed "invisible disabilities" because such maladies are often not readily apparent to others. This paper remedies this situation, in part, by addressing accommodations for mentally impaired students involving animals. The writer also hopes to bring some clarity to this topic in order to ensure that higher education enacts effective and lawful policies and practices.

\section{The Palliative Effects of Animals}

Although students seeking permission to keep animals on campus to mitigate their mental impairments is relatively new, the ameliorative effects of animals are not. For centuries people have noted that animals can have a positive influence on human functioning, and conventional wisdom has long supported the use of animals in promoting human wellbeing (Nimer \& Lundahl, 2007). Recent studies have found that while many benefits of animal companionship apply to groups across the board, unique benefits were found for those individuals with mental or psychiatric disorders (The Delta Society, n.d.). Substantial research across the health sciences provides evidence of the human health benefits, including physiological, psychological, and emotional, that can be derived from human-animal interactions (Barker, Rogers, Turner, Karpf, \& Suthers-Mccabe, 2003; Hanrahan, 2013).

Yet some believe that requests to bring animals to school is being twisted and stretched to seemingly absurd dimensions by students seeking to have their pets accompany them on campus for some often vaguely described condition (McDonald, 2000). Concerns have surfaced about people abusing the system by acquiring ESAs even though they do not need them. Various animals-on-campus critics believe some students feign difficulties as a way of getting their pets to join them at school. Indeed, Jane Jarrow, president of Disability Access Information and Support, an organization that helps colleges meet disability standards, told The Chronicle of Higher Education that "the single biggest concern on the part of institutions [regarding animals] would be setting a precedent. They worry that if they say yes to this one, they won't be able to say no to the next one" (Field, 2006, p. 15)-resulting in college campuses resembling zoos rather than learning communities.

\section{CAMPUS OCCURRENCES}

Several campus incidents provide background information on this issue. In 2005, freshman Sarah Sevick, diagnosed with anxiety and depression, petitioned administrators at Our Lady of the Lake University in San Antonio, Texas, to let her bring her ferret, Lilly, to her dorm room and her classes because Lilly helped her cope and calmed her during her panic attacks (Field, 2006). Ms. Sevick considered her ferret to be no less legitimate than a guide dog even though the support Lilly provided was emotional, rather than physical. When her request was denied, Ms. Sevick filed a complaint with the U.S. Department of Justice (DOJ), but the agency refused to take action on her grievance. But even as the college won, they lost financially due to incurred legal expenses.

Similarly, Kyra Alejandro, a student at Palm Beach State College in Palm Beach, Florida, was diagnosed in 2011 with various mental disorders, and as soon as she received her diagnosis, she began training her dog, a black Pomeranian named Ambrosius, as a "psychiatric service animal." The dog was taught "to 
establish eye contact, nip her fingers, or snort when he perceived imminent panic attack." Alejandro claimed she used the dog to participate in and benefit from her education. When she failed her classes and was escorted off the campus several times, in part because two departments at the institution had different positions on allowing the dog in class, Ms. Alejandro filed suit against the school (Kyra Alejandro v. Palm Beach State College, 2011). The court held that Ms. Alejandro was an individual with a disability under the ADA and ADAAA and that Ambrosius qualified as a service animal. The court was swayed by the psychologist's statement that her dog "makes a clinical difference for Ms. Alejandro, and has proved to be a crucial accommodation, enabling her to study and learn without experiencing debilitating anxiety" (Bazelon Center for Mental Health Law, n.d.a, p. 10). The college was ordered to pay Alejandro and her counsel $\$ 100,000$.

In another case, Brittany Hamilton, who was taking prescribed medication for anxiety and depression, enrolled at the University of Nebraska at Kearney in August 2010. She registered with its disabilityservices office, disclosing that she had depression and anxiety and requested that campus officials let her ESA, a four-pound miniature Pinscher named Butch, live with her in a university apartment. The student submitted a note from her nurse indicating that the dog could help by giving Ms. Hamilton a sense of stability, building her confidence, and distracting her from anxiety. According to administrators, the student did not follow the university's psychological-documentation guidelines which asked for information regarding the student's treatment and prescribed medications, including a list of dosages and schedules for intake; the date of the student's last visit with the doctor and a schedule of regular visits; a list of any other doctors providing treatment; a clinical summary indicating the substantial life activities impaired by the disability, the extent to which these limitations would impact the academic or living environment in a postsecondary setting, and clear evidence that the student's symptoms are present in two or more settings; and an explanation of how the student's limitations affect the activities that are required in an academic environment.

After an investigation by The Department of Housing and Urban Development (HUD), the DOJ filed suit (United States v. University of Nebraska at Kearney, 2010), alleging that the University violated the Fair Housing Act (FHA, 1968) by denying a student's request to have her ESA live with her in a university apartment. In finding for the plaintiff, the court noted that "particularly in the context of residential settings ... there may be a legal obligation to permit the use of animals that do not qualify as service animals under the ADA, but nonetheless provide necessary emotional support to persons with disabilities" (42 U.S.C. 3604(f)(3)(b)). Moreover, the DOJ determined that the university had discriminated against the student by requiring "detailed disability information that goes beyond what is needed to review a request for reasonable accommodation in housing" and that administrators violated the federal FHA by "illegally inquiring into the nature and severity" of the student's disability, as well as by "refusing to make a reasonable accommodation to modify their no-pet policy."

These accounts highlight the ongoing struggle that many colleges encounter when trying to understand and comply with various laws that apply to student requests for exceptions to a school's no-pets policy as an accommodation for their mental disability. This effort is complicated by various animal definitions and labels. 


\section{ANIMALS ON CAMPUS}

The use of animals in various service, assistive, therapeutic, pet, and emotional support roles has contributed to an uncoordinated and confusing expansion of labels. Parenti, Foreman, Meade, and Wirth (2013) summarize these numerous names to include "service animals," "companion animals," "comfort animals," "emotional support animals," "visitation animals," "therapy animals," "therapy/emotional support animals," "assistive animals," "assistance animals," "psychiatric service animals," and "pets." This inconsistent vocabulary leads to difficulties many universities encounter when making decisions regarding animals on campus. To further complicate matters, definitions of animals differ from jurisdiction to jurisdiction. While it is beyond the scope of this paper to discuss more local differences, Wisch (2012)-from the Animal Legal \& Historical Center at Michigan State University College of Law - skillfully compares all 50 state's assistance animal laws.

Nevertheless, for our purposes, several definitions are significant: service animals, ESAs, and pets. Table1 shows these definitions along with a brief statement indicating where animals are generally allowed on campus. ESAs and service animals are not "pets," but are considered to be more like assistive aids, such as wheelchairs.

Table 1

Key animal categories relevant to colleges and locations where they are generally allowed

Service Animals

Dogs generally allowed in all campus locations

\section{Emotional Support} Animals (ESAs)

Generally allowed in student housing and in student campus jobs

\section{Pets}

Generally not allowed in any campus location

\section{Service Animals}

Service animals must generally be provided access to all campus locations. Guide dogs that assist people with visual impairments or blindness are the archetypal example of a service animal. The DOJ (2011) defines a service animal as "any dog [some exceptions for a miniature horse] that is individually trained to do work or perform tasks for the benefit of an individual with a disability, including a physical, sensory, psychiatric, intellectual, or other mental disability" (p. 56269). Other species of animals are not service animals for the purposes of this definition. The DOJ is explicit that the following animals are not considered service animals under the ADA and ADAAA: 1) any animals besides dogs; 2) animals that serve solely to provide a crime deterrent effect; and 3) emotional support, comfort, or companionship animals (DOJ, 2011).

The work or tasks performed by a service animal must be directly related to the individual's disability and can include a wide variety of services, such as assisting those with low vision, alerting individuals who are hard of hearing, pulling a wheelchair, and retrieving items such as medicine or the telephone. 
With respect to mental disabilities, service animals may perform a variety of critical functions that assist many individuals with psychiatric disabilities, including alleviating symptoms of PTSD, anxiety disorders, and panic disorders by calming the handler and reducing physical and mental effects like severe depression, preventing or interrupting impulsive or destructive behaviors, such as self-mutilation, and interrupting inappropriate repetitive behavior with a persistent nudging task.

A service animal may be trained by a non-certified professional, a friend, a family member, or the person with the disability. Service animals are working animals and must be harnessed, leashed, or tethered, unless these devices interfere with the animal's work or the individual's disability prevents using these devices. In that case, the person must maintain control of the animal through voice, signal, or other effective controls. A service dog is not required to be registered or wear a special tag or vest identifying it as a service animal.

When it is not obvious what service an animal provides, staff may onlyask only two questions: (1) Is the dog a service animal required because of a disability? and (2) What work or task has the dog been trained to perform? Any inquiry beyond these two questions opens up organizations to litigation. Consequently, administrators cannot ask about the person's disability, require medical documentation, require a special identification card or training documentation for the dog, or ask that the dog demonstrate its ability to perform the work or task.

Safety considerations for denying an accommodation must be based on actual risks, rather than on mere speculation, stereotypes, or generalizations about individuals with disabilities or about a dog's breed (e.g., Pit Bull). A perceived threat without evidentiary basis will not likely support exclusion. Moreover, there is no specific legal requirement as to the amount or type of work a service animal must provide.

\section{ESAs}

ESAs (sometimes called therapy animals or support animals) are typically dogs and cats, but may include other animals of any species that provide support, well-being, comfort, aid, or a calming influence through companionship, non-judgmental positive regard, affection, and a focus in life simply by being close to their handler. Such animals, by their very nature and mere presence, and without specific training, may relieve and/or help reduce psychologically or emotionally induced pain in persons with certain medical conditions (Pet Ownership for the Elderly and Persons with Disabilities, 2008). Because they are not individually trained to perform work or tasks, ESAs are not service animals but may be effective at ameliorating the symptoms of psychiatric disabilities by providing therapeutic nurture and support.

The principal service that ESAs provide is simply companionship. Moreover, while service animals are trained to behave flawlessly in public, ESAs may or may not be as well-behaved and may cause problems that a trained service animal may not. For instance, due to the lack of training, an ESA may bark and smell other people, whereas service dogs are trained not to do so (Witz, 2013). As such, ESAs are virtually indistinguishable from the family pet. One more source of confusion for universities is that a variety of animal types can be claimed as ESAs, including rabbits, hamsters, snakes, and potbellied pigs. 
Additionally, there is a valid distinction between the functions animals provide to persons with disabilities in the public arena (i.e., performing tasks enabling individuals to use public services and public accommodations) as compared to how ESAs might be used in a student's dwelling. For example, ESAs may provide very private functions for persons with mental and emotional disabilities. Specifically, ESAs by their very nature, and without training, may relieve depression and anxiety, and help reduce stress-induced pain in persons with certain impairments.

\section{Pets}

The term pet (from the root of the French word "petit") has long been the affectionate term for animals kept for pleasure and companionship (Grier, 2006). Brigham Young University (n.d.), often cited as having a model policy for animals on campus service, defines a pet as an animal kept for ordinary use and companionship. Pets are not considered service animals or ESAs, and most universities have not usually permitted them on campus. Importantly, what identifies ESAs from pets is that the student owner/handler has been diagnosed by a medical professional as having a verifiable (mental) disability that is not transitory and minor. This is explained in greater detail below.

\section{MENTAL IMPAIRMENTS}

Mental or psychiatric impairments refer to the collection of all diagnosable mental disorders causing severe disturbances in thinking, feeling, relating, and functional behaviors which can result in a markedly diminished capacity to cope with the demands of daily life. More formally, Federal laws define a person with a disability as "Any person who has a physical or mental impairment that substantially limits one or more major life activities; has a record of such impairment; or is regarded as having such an impairment" (e.g., ADA, Section 12102). Under the ADAAA, "major life activities" was expanded to include a non-exhaustive list of "major bodily functions." Specifically, the ADAAA indicates:

- Major life activities include, but are not limited to, caring for oneself, performing manual tasks, seeing, hearing, eating, sleeping, walking, standing, lifting, bending, speaking, learning, reading, concentrating, thinking, communicating, and working.

- Major bodily functions include, but are not limited to, functions of the immune system, normal cell growth, digestive, bowel, bladder, neurological, brain, endocrine, respiratory, circulatory, and reproductive functions (U.S. Department of Labor, n.d.).

A mental impairment includes any mental or psychological disorder, such as mental retardation, organic brain syndrome, emotional or mental illness, and specific learning disabilities, as well as psychological disorders or emotional or mental illnesses including depression, bipolar disorder, anxiety disorders (including PTSD), schizophrenia, personality disorders, and other similar conditions identified in the American Psychiatric Association's Diagnostic and Statistical Manual of Mental Disorders (2013; DSM-5) that significantly limits one or more major life activities. It is not necessary that the disability be an obvious one. 
It is noteworthy that some conditions included in the DSM-5 are excluded under the ADA, including kleptomania, pyromania, exhibitionism, voyeurism, transvestitism, substance abuse problems, and transsexualism. Moreover, some mental disability claims filed under the ADA have involved "fanciful conditions" not found in the DSM-5, including "chronic lateness syndrome," "sexual impulse control disorder," and "authority figure stress reaction syndrome" (Rosenberg, 2013), and have not been classified as impairments requiring accommodation.

Furthermore, individuals who claim to be worried or uneasy over marital problems, financial hardships, roommate difficulties, class duties, or harsh and unreasonable treatment from instructors are not classified as disabled. Additionally, traits or behaviors are not, in themselves, mental impairments. For example, stress, in itself, is not automatically a mental impairment; stress, however, may be shown to be related to a mental or physical impairment. Similarly, traits like irritability, quick temper, chronic lateness, and poor judgment are not, in themselves, mental impairments, although they may be linked to mental disorders.

\section{ADDRESSING STUDENT ANIMAL REQUEST ACCOMMODATIONS}

After receiving a student request for an accommodation to bring an animal on campus, an administrator must consider the following:

1. Why is the student requesting an exception to the college's policy of no animals on campus? This should give the administrator information on what animal category (i.e., pet, ESA, service animal) the student is requesting. Administrators must be able to interpret the student's request broadly and should not disqualify a student who did not use exact wording such as an ESA or service animal.

a. Pet. If it is determined that the animal is a pet then the student would normally not be permitted to keep it on university property or in university housing.

b. Service animal. If it appears that the animal is a service animal then the animal is exempt from the university's no-pet policies and is permitted to accompany its owner at all times and in all areas of the premises where persons are normally allowed to go, except where animals are specifically prohibited (e.g., custodial closets, boiler rooms, wood and metal shops). When it is not obvious what service an animal provides, only limited inquiries are allowed, as indicated earlier (e.g., Is a dog a service animal required because of a disability? What work or task has the dog been trained to perform?). A school may not make the two permissible inquiries set out above when it is readily apparent that the animal is trained to do work or perform tasks for an individual with a disability (e.g., the dog is observed guiding an individual who is blind).

C. ESA. If the animal is an ESA, then the student is permitted to keep the animal at his/her residence and to have the animal accompany them to their campus jobs. Documentation of the need for an ESA should include the following: 
i. A letter from the student explaining the need for the animal, the type of animal, a description of the animal, the animal's name, whether the animal is housebroken, the date[s] of the medical examinations and prescriptions specifying the need for such the animal, and the date when the animal was acquired.

ii. A signed letter, on professional letterhead, from the student's physical or mental healthcare provider or licensed therapist or other qualified professional that includes, at a minimum, the nature of the applicant's disability, the provider's opinion that the condition affects a major life activity, how the animal is necessary to provide the impaired student access to the university's housing or employment settings, and the relationship between the disability and the assistance the animal provides.

2. Is the student's accommodation request reasonable? Here administrators may consider whether granting the request would constitute an undue financial or administrative burden, or would fundamentally alter the nature of the institution. In addition, animal accommodation requests may be denied if (1) the specific animal in question poses a direct threat to the health or safety of others that cannot be reduced or eliminated by another reasonable accommodation, or (2) the specific assistance animal in question would cause substantial physical damage to the property of others that cannot be reduced or eliminated by another reasonable accommodation. A determination that an animal poses a direct threat of harm to others or would cause substantial physical damage to the property of others must be based on an individualized assessment that relies on objective evidence about the specific animal's actual conduct. Breed, size, and weight limitations are not applicable to ESAs. Conditions and restrictions that housing providers and employers apply to pets may not be applied to service and ESAs. For example, while housing providers may require applicants or residents to pay a pet deposit, they may not require applicants and residents to pay a deposit for ESAs.

\section{TAKEAWAYS}

There are a number of lessons for administrators regarding accommodations for mentally disabled students and "no-pets" policies. These are presented in a Top Ten Lessons list based on suggestions and observations from the National Association of College and University Attorneys (2012), the Bazelon Center for Mental Health Law (n.d.b), the Job Accommodation Network (2011), and the Animal Legal \& Historical Center at Michigan State University's College of Law (n.d.).

\section{Lesson \#1}

Be prepared to address the presence of animals on campus in the future, as this matter continues to be an evolving situation, especially as mental disorders in the student age range continue to trend upward. Additionally, students will continue to question differences between service animals and ESAs and may well bring up the fact that ESAs are permitted in university housing and so should also be permitted in other campus locations, including classrooms. Particularly astute students may even bring to an 
administrator's attention the Air Carrier Access Act of 1986 (ACAA), which allows ESAs to accompany disabled passengers in the aircraft cabin. If ESAs can travel with their handlers on an airplane, these students might say, then surely allowing ESAs in classrooms should be permitted.

Another factor that will contribute to greater demand for accommodations for service animals and ESAs involves the explosion of Internet-related sites. Multiple websites now offer certifications, registrations, endorsements, identification tags, clothing identifying the animal as a service animal or ESA, and evaluation letters from mental health professionals highlighting the disability and how the presence of an animal is beneficial to an individual's mental health. A virtual industry has developed to assist individuals qualify pets as service animals or ESAs - for a price. For example, the National Service Animal Registry (NSAR; n.d.) advertises that for only $\$ 64.95$ plus shipping and handling fees individuals get a lifetime registration, a NSAR online database listing, an official NSAR embossed certificate, two professional quality photo ID cards, and two photo ID card clips. Applicants can also purchase a vest with a round NSAR Certified patch professionally sewn to the vest for an additional $\$ 50.95$ (plus shipping and handling, of course). All that is necessary is the completion of three quick steps in which the registrant certifies by checking a box that he or she meets various qualifications. Some of these sites will arrange for a mental health professional to send the applicant a prescription letter. Perceptive administrators realize that many such sites would certify a bicycle as an ESA for a fee.

Finally, students are increasingly marketed to as "consumers" of an "experience" (Edmunson, 1997). With this orientation, universities have catered increasingly to the wishes and interests of studentsincluding better and more interesting food choices, 24-hour fitness centers, expansive new residence halls with no shared bathrooms, on-campus writing and learning centers, and student unions that resemble resorts and shopping malls-and this has created a consumer mentality among some students. A frequent consequence of such a mindset is that students believe they are entitled to and deserving of special treatment (Twenge, 2006), leading them to be more aggressive and feel more empowered to make requests that schools eliminate pet bans and relax animal policies they the students find objectionable (Cain, Romanelli, \& Smith, 2012).

\section{Lesson \#2}

Administrators must be familiar with the differences between service animals and ESAs. A service animal is trained to perform work or tasks for the benefit of a person with a disability, and reasonable accommodation must be provided in places of public accommodation and public entities (such as classrooms, libraries, theaters, and cafeterias). However, these entities may not ask for documentation, but may enly ask only if the animal is a service animal and what it is trained to do. With respect to housing, a housing provider is required to make a reasonable accommodation for a service animal and may ask for documentation that the requester of such an accommodation has a disability and that there is a disability-related need for a service animal.

An ESA is an animal that provides comfort or support for a person with a disability, but does not have any individualized training to perform work or tasks. Places of public accommodation and public entities are not required to provide reasonable accommodation for ESAs, but are required to provide reasonable accommodation in housing contexts (such as university-owned or contracted housing). Additionally, 
housing providers may ask for documentation that the requester of such an accommodation has a disability and there is a disability-related need for an ESA.

\section{Lesson \#3}

Postsecondary institutions should consider having only one university office to which all staff, student, and faculty questions about animals on campus should be directed. This will decrease the possibility of two or more departments having contradictory findings, as was the case in Kyra Alejandro v. Palm Beach State College (2011). This department's responsibility should be clearly communicated to all interested parties in the university community, especially those in university housing.

\section{Lesson \#4}

Institutions should not ask for any overly intrusive, burdensome, confidential, unnecessary documentation, or information with respect to an accommodation for a student, but limit the amount of information requested for an accommodation and avoid asking for excessive material, as was the situation with United States v. University of Nebraska at Kearney (2012). Generally, if the resident's disability and need for the animal is evident, then institutions should not ask for additional information from a student. If the disability is evident, but the need for the animal is not, the institution is authorized to request only the specific data necessary to evaluate the disability-related need.

But in situations where neither the disability nor the need for the animal are obvious, the school may request disability-related information that first verifies the condition as any that substantially limits one or more of the person's major life activities; second, describes the need for the requested accommodation; and finally, demonstrates the relationship between the resident's disability and the need for reasonable accommodation.

This inquiry must not be highly intrusive, and in most cases, an individual's medical records or detailed information about the nature of their disability is not necessary. While a university does have a right to conduct a meaningful review when asked to grant exemptions to the institution's rules and policies, it needs to be careful not to request details that go beyond that required to obtain the necessary information.

\section{Lesson \#5}

Institutions should not focus a great deal on trying to determine if the student has a disability. Employers can also expect that ADA cases are likely to move from "threshold" issues (whether an employee has a disability) to "liability" issues (whether the employee actually was discriminated against and the organization failed to provide reasonable accommodation). While every impairment may not be a disability, employers will often need to assume disability and attempt reasonable accommodation. Moreover, schools should clearly state that requests for animals on campus and exemptions from nopets rules will be decided on a case-by-case basis. 


\section{Lesson \#6}

Context matters. As colleges and universities strive to accommodate their students, they must do so against a bewildering backdrop of antidiscrimination laws which impose differing obligations that apply to different campus locations. There are three key areas that universities must consider: campus facilities other than housing, campus housing, and campus sites where students are employed by the university. It should be noted that people with disabilities often have more protections in a housing context than elsewhere. For example, a cat that provides emotional support to a person could be permitted as a reasonable accommodation in a student dwelling; however, the same cat would not be covered by the ADA's more narrow definition of "service animal" and could not come into an employment setting.

Similarly, it is imperative that administrators recognize that compliance with the Fair Housing Administration and Section 504 of the Rehabilitation Act (1973; a federal law designed to protect the rights of individuals with disabilities in programs and activities that receive federal financial assistance from the U.S. Department of Education) does not ensure compliance with the ADA and vice versa. Importantly, universities and their housing facilities many not use the ADA definition of a service animal as a justification for reducing their FHA or Section 504 obligations. To commenters who objected that HUD was creating different standards than those issued by the DOJ under the ADA, HUD noted:

There is a valid distinction between the functions animals provide to persons with disabilities in the public arena, i.e., performing tasks enabling individuals to use public services and public accommodations, as compared to how an assistance animal might be used in the home. For example, ESAs provide very private functions for persons with mental and emotional disabilities. Specifically, ESAs by their very nature, and without training, may relieve depression and anxiety and help reduce stress-induced pain in persons with certain medical conditions affected by stress. Conversely, persons with disabilities who use ESAs may not need to take them into public spaces covered by the ADA. (U.S. Department of Housing and Urban Development, 2008, p. 63836)

Consistent with this view, recent enforcement actions and lawsuits filed by HUD and the DOJ indicated their clear belief that the FHA extends to housing at educational institutions (U.S. Department of Housing and Urban Development, 2014; United States v. University of Nebraska at Kearney, 2012).

\section{Lesson \#7}

It is important not to forget about municipal and state laws that may impact an institution. Complicating the analysis of when an animal must be allowed in public accommodations is the fact that many state (and municipal) laws do not directly parallel the federal laws discussed above. For example, Minnesota law uses the term "support animal"; Maryland law uses the term "service animal"; and Nevada uses both "support animal" and "service animal." Generally, state law definitions include some reference to training, although the language can vary. In Indiana, a service animal is a "professionally trained animal." The Alaska definition states that the animal must be "certified by a school or training facility for service 
animals as having completed that training." Illinois uses the language that an animal is "trained in obedience and task skills."

The focus of some of these definitions may be on the impact of having the animal for the person with the disability. An example is the language in Minnesota law that states that the animal "accompanies a person with a disability to assist in managing the disability and enables the person to perform functions that the person would otherwise be unable to perform." Likewise, many municipalities have a number of requirements include vaccinations, licensure, ID tags, etc. These should be incorporated in appropriate college policies.

\title{
Lesson \#8
}

Administrators must be prepared to address other students' concerns. There may be individuals on campus with legitimate grounds to object to the presence of animals in residence halls, classrooms, and other buildings based on allergies, phobias, or other psychological or physiological problems with animals. Balancing the needs of both sets of students presents a greater level of complexity, but the DOJ has been clear that institutions must do exactly that:

\begin{abstract}
Allergies and fear of dogs are not valid reasons for denying access or refusing service to people using service animals. When a person who is allergic to dog dander and a person who uses a service animal must spend time in the same room or facility, for example, in a school classroom . . . they both should be accommodated by assigning them, if possible, to different locations within the room or different rooms in the facility. (DOJ, 2011)
\end{abstract}

Furthermore, the DOJ's guidance on service animals also indicated that "people with disabilities who use service animals cannot be isolated from other patrons, treated less favorably than other patrons, or charged fees that are not charged to other patrons without animals (2011).

\section{Lesson \#9}

The expected increased incidence of mental disorders will lead to increased requests for accommodations. Moreover, critics of the new DSM-5 manual, which was published in 2013, feel that thresholds for the diagnosis of many disorders have been lowered and many people whose behavior is not currently considered "disordered" will, under the new manual, now be labeled as ill. What was once considered psychologically healthy (or at least not unhealthy) is presently considered a mental illness. For instance, people who are extremely shy and concerned about how others might evaluate them, and who thus avoid certain types of activities, might be diagnosed with "avoidant personality disorder." These same characteristics were not historically considered pathological, and in some other cultures they are not thought to be so. Some of the behaviors, beliefs, and feelings that were within the thennormal range of human experience are now deemed to be pathological. Thus, the actual definition of mental illness has broadened, creating a bigger tent with more people under it (Rosenberg, 2013). 
Another way that the increased prevalence of mental illness occurs is by lowering the threshold of what it takes to be diagnosed with a given malady. For instance, DSM-5 changed the criteria for "generalized anxiety disorder," a disorder that involves excessive and persistent worrying. Whereas the criteria in DSM-IV (American Psychiatric Association, 1994) required three out of six symptoms of worrying, only one symptom is needed in DSM-5. Similarly, whereas in DSM-IV the symptoms must have persisted for at least six months, in DSM-5 the duration has been reduced to three months. This means that if a person is excessively worried for three months about their finances or their health (to the point where they cannot control their worries), they would be considered to have an illness, whereas in the past they would not have.

\section{Lesson \#10}

Administrators should also address responsibilities of persons with service animals or ESAs. The accommodated student must understand that $s /$ he is responsible for ensuring the clean-up of the animal's waste and, when appropriate, must toilet the animal in areas designated by the university consistent with the reasonable capacity of the owner. Additionally, the owner/handler must comply with following concerns:

1. In accordance with local ordinances and regulations, animals may be required to be immunized against diseases common to that type of animal. Dogs must have current vaccination against rabies and wear a rabies/license/vaccination tags verifying that the shots required by law have been given. Although not mandated, cats should have the normal shots required for a healthy animal. Local licensing requirements should be followed.

2. Animals, other than cats and dogs, to be housed in university dwellings must have an annual clean bill of health from a licensed veterinarian. Documentation can be a vaccination certificate for the animal or a veterinarian's statement regarding the animal's health. The university has authority to direct that animals receive veterinary attention.

3. If appropriate the animal (e.g., dog) must be on a leash, unless the leash would inhibit the animal's ability to be of service.

4. Administrators may want to give notice to students when animals may be asked to be removed. This might include something to the effect that a student may be directed to remove an animal that is unruly or disruptive (e.g., barking excessively, jumping up on people) if the handler is unable or unwilling to take effective action to control the animal. Repeated instances of such behavior may result in exclusion of the animal from university facilities until the student can demonstrate that $\mathrm{s} /$ he can effectively regulate the animal. The student must also ensure that the animal is kept clean and well-groomed. Animals that are excessively unclean (e.g., repeated soiling of facilities, flea-infested, foul-smelling and/or shedding excessively) may be excluded from university facilities. 


\section{SUMMARY AND CONCLUSION}

Even as a dog is said to be "man's best friend" [sic], students realize at many U.S. colleges that their best friend is often not welcome. However, it is not only students' best friends that are banned, but other friends as well, since many postsecondary institutions do not allow any animals on campus (except such animals as guide dogs, laboratory or research animals, fish in small aquariums). It is hoped that this paper will assist administrators address the topic of ESAs on campus.

The aim of most universities is to promote a welcoming and inclusive campus that ultimately supports success for all stakeholders including persons with mental disabilities. The right of an individual with a mental disability to a service animal or ESA depends on the type of animal, the function that the animal performs, and the setting in which the right is asserted. Different state and/or federal laws apply to different situations. Under federal law, service animals are covered by Section 504 of the Rehabilitation Act, the ADA, the FHA, and the ACAA. ESAs are covered by the FHA and the ACAA.

There are specific definitions of "service animals" in the law, and there are different definitions depending on where the animal is being taken. The ADA contains a definition of service animals that applies only in the context of taking an animal into certain types of public spaces. In the context of housing, the broader term of assistance animal is used and the Fair Housing Administration is the regulatory authority.

ESAs provide comfort to a person with a psychiatric disability, but are not trained to perform specific tasks to assist them. However, ESAs may be allowed to accompany individuals in housing as "reasonable accommodations" or "reasonable modifications" for the individual's disability. ESAs under the FHA, unlike service animals, are not limited to dogs. The obligation to make reasonable accommodations includes a requirement that housing providers make exceptions to a "no-pets" policy to permit persons with disabilities to use and live with either a service animal or ESA. This means that, in addition to service animals, ESAs and animals that provide some type of disability-related assistance may be permitted as an accommodation in housing.

Finally, it should be noted that some universities-mostly private-recognize the importance of animals to their owners and have adopted their pet friendly campuses as a marketing technique to recruit new students. They view pets on campus as a strategic opportunity and believe this provides them a competitive advantage. These colleges have taken the concept of "the comforts of home" a step further and are allowing students to bring animals on campus. Some schools have dedicated entire dorms (or wings within dorms) to students with pets, while others have also extended pet-owning agreements to Greek fraternity and sorority house members. For example, at Eckerd College in St. Petersburg, Florida, residential students can have one pet (e.g., cats, dogs, ducks) and two domestic animals (e.g., gerbils, sugar gliders, reptiles less than 6 feet long and nonvenomous; Eckerd College, n.d.).

\section{REFERENCES}

The ADA Amendments Act of 2008, PL 110-325 (S 3406).

Air Carrier Access Act of 1986. Public Law 99-435.

VON BERGEN / DOI: 10.5929/2015.5.1.3 
American Psychiatric Association. (1994). Diagnostic and statistical manual of mental disorders (IV ${ }^{\text {th }}$ ed.): DSM-IV. Alexandria, VA: American Psychiatric Association.

American Psychiatric Association. (2013). Diagnostic and statistical manual of mental disorders ( $5^{\text {th }}$ ed.): DSM-5. Alexandria, VA: American Psychiatric Association.

The Americans with Disabilities Act of 1990, 42 U.S.C. $§ 12112(b)(5)$.

Animal Legal \& Historical Center. (n.d.). Retrieved from https://www.animallaw.info/site/animal-legaland-historical-center-web-site

Barker, S. B., Rogers, C. S., Turner, J. W., Karpf, A. S., \& Suthers-Mccabe, H. M. (2003).

Benefits of interacting with companion animals: A bibliography of articles published in refereed journals during the past five years. The American Behavioral Scientist, 47(1), 94-97.

Bazelon Center for Mental Health Law. (n.d.a). Kyra Alejandro, Plaintiff v. Palm Beach State College et al. Retrieved from https://www.bazelon.org/LinkClick.aspx?fileticket=Rs5_lly_Riw\%3D\&tabid=600

Bazelon Center for Mental Health Law. (n.d.b). Retrieved from http://www.bazelon.org/

Blanco, C., Okuda, M., Wright, C., Hasin, D. S., Grant, B. F., Liu, S. M., \& Olfson, M. (2008).

Mental health of college students and their non-college-attending peers: Results from the national epidemiologic study on alcohol and related conditions. Archives of General Psychiatry, 65(12), 1429-1437.

Brigham Young University. (n.d.). Family Housing Policies. Retrieved from http://www.byu.edu /oncampushousing/fam_policies.shtml

Cain, J., Romanelli, F., \& Smith, K. M. (2012). Academic entitlement in pharmacy education. American Journal of Pharmacy Education, 76(10), 89.

Degutis, K. (2014). What's Trending? Retrieved from http://thelyst.com/featured/whats-trending-4/

The Delta Society (recently renamed Pet Partners). (n.d.). Fair Housing Information Sheet \# 6, Right to Emotional Support Animals in "No-pet" Housing. Retrieved from http://www.bazelon.org /LinkClick.aspx?fileticket=mHq8GVOFI4c\%3D\&tabid

Dessler, G. (2015). Human resource management (14 ${ }^{\text {th }}$ ed.). Upper Saddle River, NJ: Pearson.

Eckerd College. (n.d.). Pet Policy. Retrieved from http://www.eckerd.edu/housing/petlife/petpol icy.php

Edmunson, M. (1997, September). On the uses of a liberal education as lite entertainment for bored college students. Harper's, 295, 39-49.

Eiser, A. (2011). The crisis on campus: APA working with Congress to address serious mental health problems on college campuses. Monitor on Psychology, 42(8), 18.

Fair Housing Act of 1968, 42 U.S.C.A. §§ 3601-3631.

Field, K. (2006, October 13). These student requests are a different animal. Chronicle of Higher Education, 53(8), 15. 
Grier, K. (2006). Pets in America: A history. New York: Harcourt.

Grossman, P. D. (2009). Foreword with a challenge: Leading our campuses away from the perfect storm. Journal of Postsecondary Education and Disability, 22(1), 4-9.

Hanrahan, C. (2013). Social work and human animal bonds and benefits in health research: A provincial study. Critical Social Work, 14(1), 63-79.

Huss, R. J. (2012). Canines on campus: Companion animals at postsecondary educational institutions. Missouri Law Review, 77(2), 418-479.

Job Accommodation Network. (2011). Accommodation and Compliance Series: Service Animals in the Workplace. Retrieved from http://askjan.org/media/servanim.html

Kessler, R. C., Berglund, P., Demler, O., Jin, R., Merikangas, K. R., \& Walters, E. E. (2005). Lifetime prevalence and age-of-onset distributions of DSM-IV disorders in the National Comorbidity Survey Replication. Archives of General Psychiatry, 62(6), 593-602.

Kruisselbrink-Flatt, A. (2013). A suffering generation: Six factors contributing to the mental health crisis in North American higher education. College Quarterly, 17(1), 1-17.

Kyra Alejandro v. Palm Beach State College, 843 F. Supp. 2d 1263 (S.D. Fla., Nov 7, 2011).

McDonald, J. J. Jr. (2000). The Americans with difficult personalities act. Employee Relations Law Journal, 25(4), 93-107.

Moss, K., Johnsen, M., \& Ullman, M. (1998). Assessing employment discrimination charges filed by individuals with psychiatric disabilities under the Americans with Disabilities Act. Journal of Disability Policy Studies, 9(1), 81-105.

The National Alliance on Mental Illness. (2013). Mental Illness Facts and Numbers. Retrieved from http://www.nami.org/factsheets/mentalillness_factsheet.pdf

National Association of College and University Attorneys. (2012). Update on accommodating service and assistance animals on campus: Making heads or tails of federal disability laws.

NACUANOTES, 10(6). Retrieved from http://www.higheredcompliance.org/resources/resources /ServiceAnimalsUpdate.pdf

National Service Animal Registry. (2006). Retrieved from http://www.nsarco.com/

Nimer, J., \& Lundahl, B. (2007). Animal-assisted therapy: A meta-analysis. Anthrozoos: A Multidisciplinary Journal of the Interactions of People \& Animals, 20(3), 225-238.

Parenti, L., Foreman, A., Meade, J. B., \& Wirth, O. (2013). A revised taxonomy of assistance animals. Journal of Rehabilitation Research \& Development, 50(6), 745-756.

Pet Ownership for the Elderly and Persons with Disabilities: Final Rule, 73 Fed. Reg. 208, 63836 (Oct. 27, 2008) (codified at 24 C.F.R. pt. 5).

Post-9/11 Veterans Educational Assistance Act of 2008, 38 U.S.C. Chapter 33.

Rehabilitation Act of 1973, Pub. L. No. 93-112, 87 Stat. 394 (Sept. 26, 1973). 
Rosenberg, R. S. (2013). Abnormal Is the New Normal: Why Will Half of the U.S. Population Have a Diagnosable Mental Disorder? Retrieved from http://www.slate.com/articles /health_and_science/medical_examiner/2013/04/diagnostic_and_statistical_manual_fifth_editi on_why_will_half_the_u_s_population.html

Rothstein, L., \& Rothstein, J. (2009). Disabilities and the law ( $4^{\text {th }}$ ed.). Eagan, MN: Thomson Reuters.

Twenge, J. M. (2006). Generation me: Why today's young Americans are more confident, assertive,entitled-and more miserable than ever before. New York: Free Press.

Twenge, J. M., Gentile, B., DeWall, C. N., Ma, D., Lacefield, K., \& Schurtz, D. R. (2010). Birth cohort increases in psychopathology among young Americans, 1938-2007: A cross-temporal metaanalysis of the MMPI. Clinical Psychology Review, 30(2), 145-154.

U.S. Department of Housing and Urban Development. (2008, October). Pet ownership for the elderly and persons with disabilities; Final rule. Federal Register, 73(208), p. 63836.

U.S. Department of Housing and Urban Development. (2014, August). HUD Charges Kent State University with Housing Discrimination. Retrieved from http://portal.hud.gov /hudportal/HUD?src=/press/press_releases_media_advisories/2014/HUDNo_14-099

U.S. Department of Justice. (2010, September 10). Rules and Regulations. Federal Register, 75(178), 56269.

U.S. Department of Justice. (2011, July). Service Animals. Retrieved from http://www.ada.gov /service_animals_2010.htm

U.S. Department of Labor. (n.d). The ADA Amendments Act of 2008: Frequently Asked Questions. Retrieved from: http://www.dol.gov/ofccp/regs/compliance/faqs/ADAfaqs.htm\#Q5

United States v. University of Nebraska at Kearney, 672 F.3d 81, 88-89 (1st Cir. 2012).

University of California at Santa Cruz. (n.d.). Are Pets Allowed? Retrieved from http://housing .ucsc.edu/faq/\#pets

Watkins, D. C., Hunt, J., \& Eisenberg, D. (2012). Increased demand for mental health services on college campuses: Perspectives from administrators. Qualitative Social Work, 11(3), 319-337.

Wisch, R. R. (2012). Table of State Assistance Animal Laws. Retrieved from https://www.animallaw info/topic/table-state-assistance-animal-laws

Witz, B. (2013, November 15). Emotional Support, With Fur, Draws Complaints on Planes. The New York Times. Retrieved from http://www.nytimes.com/2013/11/16/business/emotional-support-withfur-draws-complaints-on-planes.html?_r=2\&

\section{ABOUT THE AUTHOR}

C. W. "Von" Von Bergen, Ph.D. (Purdue University) is the John Massey Professor of Management at Southeastern Oklahoma State University, Durant, Oklahoma. He is an industrial psychologist and is the author and co-author of numerous publications in the psychology, general management, education, and 
human resources areas. Correspondence may be directed to C. W. Von Bergen, Ph.D., John Massey John Massey School of Business, Department of Management \& Marketing, Southeastern Oklahoma State University, 211 Russell Building, 1405 N. 4th Avenue, PMB 4103, Durant, Oklahoma 74701-0609. Phone: (580) 745-2430. Email: cvonbergen@se.edu 